\title{
Reproductive disturbances and phosphoglucoisomerase instability in Festuca arundinacea (tall fescue) plants regenerated from callus and cell suspension cultures
}

\author{
A. GARCÍA, S. J. DALTON \& M. O. HUMPHREYS* \\ Institute of Grassland and Environmental Research, Aberystwyth, Dyfed SY23 3EB, U.K.
}

\begin{abstract}
Shoot tips of four Festuca arundinacea Schreb. genotypes (breeder's lines) were cultured in vitro in order to induce callus formation. In addition, cell suspension cultures were established from some of the calli. Plants were regenerated after at least 1 month under callus culture, and all of them remained hexaploid, except for one mixaploid. The flowering response was greatly altered, with some plants flowering without vernalization in the first year after culture, and one plant which did not flower even in the second year. Chromosome aberrations (reciprocal translocations, paracentric inversions, sticky chromosomes and deletions) were present in all genotypes, even after only 1 month in callus culture. There was probably an isochromosome in one plant regenerated from cell suspension culture. Abnormal microsporogenesis affecting pollen sterility was common and genotype dependent. Two genotypes showed instability at the phosphoglucoisomerase $(P G I-2)$ isozyme locus.
\end{abstract}

Keywords: Festuca arundinacea, isozymes, meiotic analysis, pollen sterility, somaclonal variation.

\section{Introduction}

Somaclonal variation (SCV) in in vitro cultures occurs as a result of a variety of mechanisms and factors (see review by Karp, 1991). Auxins in callus-inducing media can produce rapid disorganized growth which may lead to genetic instability through the occurrence of asynchronous cell divisions (Gould, 1984; Lee \& Phillips, 1988). This can result in chromosomal aberrations such as breakages caused by delayed heterochromatin replication (Eizenga, 1989). Other causes of somaclonal variation include the physical (temperature and light) and chemical (medium composition) environment through oxidative damage by free radical production (Benson, 1990).

Chromosomal aberrations such as aneuploidy increase in frequency with age of the culture (Ahloowalia, 1983). Parent plants in which meiotic and other cytological abnormalities are common will also often be more susceptible to genetic changes in culture. Selection for improved performance in culture will favour particular genotypes at the expense of others

*Correspondence.
(Bayliss, 1980). It is now possible to regenerate whole tall fescue plants even from protoplasts using genotypes selected for embryogenic response (Dalton, 1988). However, for breeding purposes, it is necessary to culture a wider range of genotypes. This study was conducted to look at SCV in breeder's lines unselected for tissue culture.

\section{Material and methods}

\section{Callus culture and cell suspension culture}

Four plants from Festuca arundinacea Schreb. breeder's lines (genotypes 1-4) were cultured in 1991. Tillers from glasshouse grown plants were surface-sterilized in sodium hypochlorite solution ( 7 per cent available chlorine) for $10 \mathrm{~min}$ and rinsed in sterile water. Shoot tips were excised and cultured on callus induction medium and grown at $25^{\circ} \mathrm{C}$ in continuous indirect light $\left(30 \mathrm{E} \mathrm{m}^{-2} \mathrm{~s}^{-1}\right)$ for 4 weeks. Resulting embryogenic calli were subcultured to fresh callus medium or placed in liquid suspension culture medium. Fresh medium was either added weekly or replaced every week for 5 weeks to suspension cultures until there was sufficient tissue to subculture. 


\section{Plant regeneration}

Suspension culture colonies were plated to embryoid maturation medium and cultured at $20^{\circ} \mathrm{C}$ in continuous cool white fluorescent light $\left(110 \mathrm{E} \mathrm{m}^{-2} \mathrm{~s}^{-1}\right)$ for 5 weeks. Embryoids and regenerating shoots were transferred to regeneration medium.

\section{Culture media}

Media based on Murashige \& Skoog (1962) were used throughout. Callus induction medium contained 3 per cent sucrose, $3 \mathrm{mg} \mathrm{L}^{-1}$ 2,4-dichlorophenoxyacetic acid (2,4-D), $0.2 \mathrm{mg} \mathrm{L}^{-1}$ 6-benzylaminopurine (BAP), 100 $\mathrm{mg} \mathrm{L}^{-1}$ casein hydrolysate and was solidified with 0.8 per cent Sigma agar. Suspension culture medium contained 3 per cent sucrose and $3 \mathrm{mg} \mathrm{L}^{-1} 2,4-\mathrm{D}$ and regeneration medium contained 3 per cent sucrose and $0.2 \mathrm{mg} \mathrm{L}^{-1}$ kinetin. All media were adjusted to $\mathrm{pH} 6.0$ before autoclaving at $121^{\circ} \mathrm{C}$ for $15 \mathrm{~min}$. Embryoid maturation medium contained 6.8 per cent glucose, 0.1 $\mathrm{mg} \mathrm{L}^{-1} 2,4-\mathrm{D}$ and $0.1 \mathrm{mg} \mathrm{L}^{-}$BAP. This medium was made double-strength, filter-sterilized and added to autoclaved Gelrite solution to give a final concentration of 0.3 per cent.

\section{Plant establishment}

Regenerated plants were potted up in three batches (Table 1).

1 Plants 1-19 were planted in pot trays and potted in a cool glasshouse by $31 / 3 / 92$.

2 Plants 20-43 were planted in pot trays and potted up by $13 / 4 / 92$ in the same glasshouse.

3 Plants $44-85$ were similarly potted up by $1 / 10 / 92$.

After 1 month's growth in pots, plants were scored visually for a number of traits (tillering, leaf width, growth habit and disease symptoms). Subsequently, plants were taken outside during the 1992-3 winter to vernalize. Plants were polycrossed in an isolation house in May 1993, and seed was harvested from individual plants in August 1993. Plant 86 (genotype 2) was regenerated in 1993, after 23 weeks in callus culture.

\section{Cytogenetics and male fertility}

For mitotic analyses root tips were collected, pretreated in chilled distilled water at $1-2^{\circ} \mathrm{C}$, fixed in a solution of 3:1 ethanol/acetic acid, hydrolysed in $1 \mathrm{~N}$ $\mathrm{HCl}$ at $60^{\circ} \mathrm{C}$ for $10 \mathrm{~min}$ and stained in Feulgen solution. The root tips were squashed in 3 per cent acetocarmine and the chromosome number determined. For meiotic studies, carried out in 22 plants, immature spikes were fixed in May 1993 in Carnoy 1 solution (6:3:1 ethanol/chloroform/acetic acid). Anthers were stained in alcoholic hydrochloric acid-carmine (Snow, 1963) and squashed in glycerine-acetocarmine for pollen counts, and in 45 per cent acetic acid for meiotic analysis.

\section{Isozyme analysis}

$P G I-2$ zymograms were recorded in 76 of the regenerated plants, plus three of the original genotypes (controls) which were grown in vitro without hormones. Horizontal starch gel electrophoresis was employed, following the procedure used by Hayward \& McAdam (1977), with the modifications introduced by Lewis et al. (1980).

\section{Results and discussion}

\section{Plant regeneration}

The four genotypes cultured in 1991 were induced to develop embryogenic calli and cell suspensions. Embryogenesis and regeneration were sporadic, but plantlets were regenerated for as long as possible. Cell suspensions of genotype 1 stopped regenerating by 12 weeks (although results are presented only for plants regenerated after 2 weeks), genotype 2 stopped regenerating by 7-8 weeks, genotype 3 by 2 weeks, and genotype 4 by 10 weeks (Table 1). The frequency and longevity of embryogenic proliferation and plant regeneration from cell suspensions was therefore low compared with genotypes selected for embryogenetic potential, from which plants could be regenerated for 30 weeks or more (Dalton, 1988; Humphreys \& Dalton, 1991).

\section{Vegetative and reproductive plant traits}

The morphology of plants derived from the same genotype was different, even within groups of plants regenerated at the same time from either callus or suspension culture (Fig. 1). Nevertheless, there were no significant morphological differences overall between plants regenerated from callus culture and those from suspension culture (data not shown) except for growth habit measured 1 month after potting (Table 2). Genotype 1 was not included in the analysis as it was represented by only three plants. The data were analysed hierarchically, and it is clear that growth habit showed a positive genotype $\times$ time in culture interaction. Thus, genotype 2 demonstrated a trend towards a prostrate plant type with length of time under culture, both for plants regenerated from callus culture and those from cell suspensions, whereas genotype 3 did not present a 
Table 1 Type of culture and 1993 seed production of Festuca arundinacea (tall fescue)

\begin{tabular}{|c|c|c|c|c|}
\hline Plant no. & Genotype & Culture & PS & $\mathrm{SS}(\mathrm{g})$ \\
\hline 1 & 1 & $1 \mathrm{mCC}+2 \mathrm{wCS}$ & - & 3.2 \\
\hline 2 & 2 & $1 \mathrm{mCC}+8 \mathrm{wCS}$ & $75^{*}$ & 3.6 \\
\hline 3 & 2 & $1 \mathrm{mCC}+5 \mathrm{wCS}$ & Low & 3.0 \\
\hline 4 & 3 & $1 \mathrm{mCC}+2 \mathrm{wCS}$ & 23 & 2.2 \\
\hline 5 & 2 & $1 \mathrm{mCC}+2 \mathrm{wCS}$ & - & 2.1 \\
\hline 6 & 4 & $1 \mathrm{mCC}$ & 92 & 6.2 \\
\hline 7 & 4 & $1 \mathrm{mCC}$ & - & 0.9 \\
\hline 8 & 4 & $1 \mathrm{mCC}$ & - & 1.6 \\
\hline 9 & 1 & $1 \mathrm{mCC}+2 \mathrm{wCS}$ & - & 3.9 \\
\hline 10 & 3 & $1 \mathrm{mCC}$ & 13 & 1.4 \\
\hline 11 & 1 & $1 \mathrm{mCC}+2 \mathrm{wCS}$ & - & 1.0 \\
\hline 12 & 3 & $1 \mathrm{mCC}$ & 12 & 2.7 \\
\hline 13 & 3 & $1 \mathrm{mCC}$ & 17 & 1.2 \\
\hline 14 & 3 & $1 \mathrm{mCC}$ & 20 & 0.5 \\
\hline 15 & 3 & $1 \mathrm{mCC}+2 \mathrm{wCS}$ & 5 & 2.3 \\
\hline 16 & 4 & $1 \mathrm{mCC}+10 \mathrm{wCS}$ & 23 & 2.8 \\
\hline 17 & 3 & $1 \mathrm{mCC}$ & - & 0.3 \\
\hline 18 & 4 & $1 \mathrm{mCC}$ & 6 & 0.3 \\
\hline 19 & 2 & $1 \mathrm{mCC}+5 \mathrm{wCS}$ & 32 & 1.1 \\
\hline 20 & 2 & $2 \mathrm{mCC}$ & 58 & 0.2 \\
\hline 21 & 2 & $2 \mathrm{mCC}$ & - & 0.1 \\
\hline 22 & 2 & $2 \mathrm{mCC}$ & High & 3.1 \\
\hline 23 & 2 & $2 \mathrm{mCC}$ & High & 2.8 \\
\hline 24 & 2 & $2 \mathrm{mCC}$ & - & 0.1 \\
\hline 25 & 2 & $2 \mathrm{mCC}$ & - & 1.5 \\
\hline 26 & 2 & $2 \mathrm{mCC}$ & 26 & 0.7 \\
\hline 27 & 2 & $2 \mathrm{mCC}$ & Low & 1.0 \\
\hline 28 & 2 & $2 \mathrm{mCC}$ & 83 & 0.7 \\
\hline 29 & 2 & $2 \mathrm{mCC}$ & 88 & 1.3 \\
\hline 30 & 2 & $2 \mathrm{mCC}$ & - & Nonflowering \\
\hline 31 & 2 & $2 \mathrm{mCC}$ & Low & 37 seeds \\
\hline 32 & 2 & $2 \mathrm{mCC}$ & - & 1.5 \\
\hline 33 & 2 & $2 \mathrm{mCC}$ & High & 3.0 \\
\hline 34 & 2 & $2 \mathrm{mCC}$ & Low & 1.9 \\
\hline 35 & 2 & $2 \mathrm{mCC}$ & Low & 8.3 \\
\hline 36 & 4 & $2 \mathrm{mCC}$ & 15 & 2.8 \\
\hline 37 & 4 & $2 \mathrm{mCC}$ & Low & 2.0 \\
\hline 38 & 4 & $2 \mathrm{mCC}$ & Low & 3.2 \\
\hline 39 & 3 & $2 \mathrm{mCC}$ & Low & 0.8 \\
\hline 40 & 3 & $2 \mathrm{mCC}$ & Low & 3.1 \\
\hline 41 & 3 & $2 \mathrm{mCC}$ & 76 & 4.0 \\
\hline 42 & 3 & $2 \mathrm{mCC}$ & - & 2.4 \\
\hline 43 & 3 & $2 \mathrm{mCC}$ & Low & 2.8 \\
\hline 44-61(except 49) & 2 & $13 w C C$ & - & Nonflowering $\dagger$ \\
\hline 49 & 3 & $12 \mathrm{wCC}$ & Low & 0.1 \\
\hline $62-85($ except 73$)$ & 2 & $18 w C C$ & - & Nonflowering ${ }^{\dagger}$ \\
\hline 73 & 2 & $18 w C C$ & 95 & $-\dagger$ \\
\hline 86 & 2 & $23 w C C$ & - & - \\
\hline
\end{tabular}

m, Months; w, weeks; CC, callus culture; CS, cell suspension; SS, seed set; PS, percent pollen stainability.

*Plant 2 had indehiscent anthers.

†Plants 56, 73, 77 and 85 flowered sporadically and heads were used for meiotic analysis. 


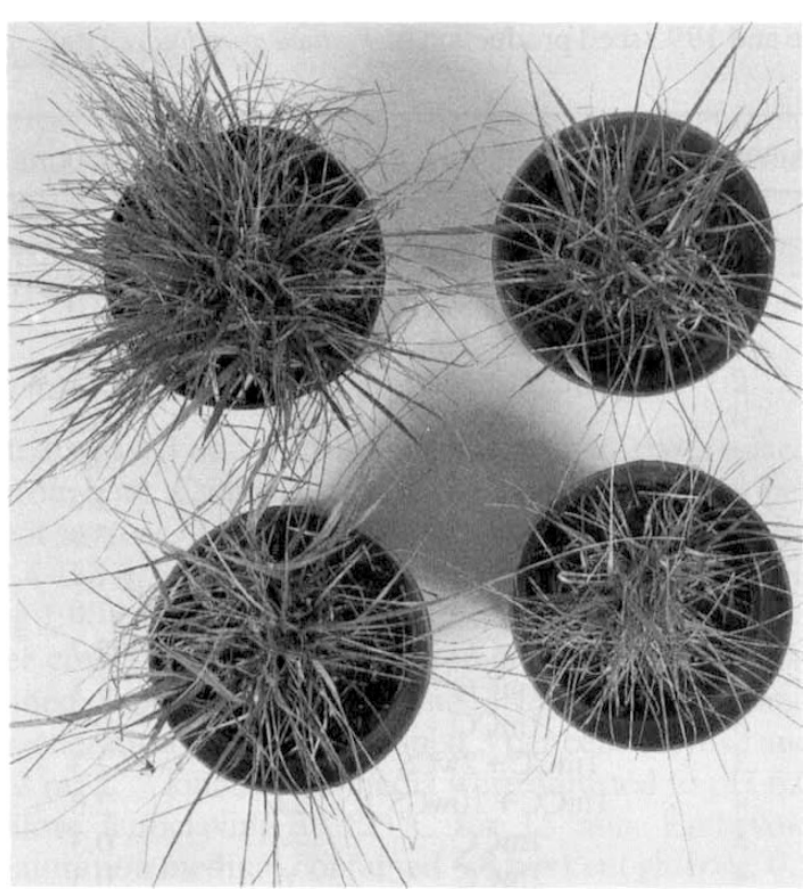

Fig. 1 Four tall fescue (Festuca arundinacea) plants of the same age derived from genotype 2 , after 18 weeks in callus culture.

clear pattern, and genotype 4 seemed to produce more erect types as time in culture increased.

In spring 1992, 12 of the 19 initial regenerants flowered, despite not being grown in vernalizing conditions ( the exceptions being plants $3,7,14,15,16,18$ and 19, which were derived from genotypes 2,3 and 4). Flowering was generally late and occurred over an extended period, from $15 / 6$ to $1 / 10 / 92$. Some of the plants were male-sterile and only plants 4 and 10 were left to set seed. However, only small seeds were produced, which did not germinate. Plants 20-86, from later batches, produced only a few sporadic heads, which were fixed for meiotic analysis. Our experience with Festuca arundinacea is that flowering ability is normally impaired during the first year following in vitro culture. The high percentage of flowering plants (>63 per cent) among initial regenerants was therefore surprising, especially as the plants were kept at $20^{\circ} \mathrm{C}$ or $25^{\circ} \mathrm{C}$ during in vitro culture until $31 / 3 / 92$, and subsequent air temperatures in April ranged from $5.6^{\circ} \mathrm{C}$ to $12.1^{\circ} \mathrm{C}$ which would not normally be sufficient for vernalization.

In spring 1993 only five plants from batch 3 flowered. However, all of the plants from batches 1 and 2 flowered, except plant 30 from batch 2 , which could be a nonflowering mutant (it remained nonflowering in 1994). This may not be unusual, since M.W. Humphreys (pers. comm.) has observed that the
Table 2 Means of growth habit scores $(5=$ erect, $1=$ prostrate) for combinations of three hierarchical treatment factors

\begin{tabular}{cccccccccc}
\hline GEN & CUL & $2 \mathrm{~W}$ & $4 \mathrm{~W}$ & $5 \mathrm{~W}$ & $8 \mathrm{~W}$ & $10 \mathrm{~W}$ & $12 \mathrm{~W}$ & $13 \mathrm{~W}$ & $18 \mathrm{~W}$ \\
\hline 1 & $\mathrm{CS}$ & 4.0 & & & & & & \\
2 & $\mathrm{CC}$ & & & 4.0 & & 2.4 & 2.6 \\
& $\mathrm{CS}$ & 4.0 & & 2.0 & 2.0 & & & \\
3 & $\mathrm{CC}$ & & 2.4 & & 1.8 & & 3.0 & & \\
& $\mathrm{CS}$ & 3.0 & & & & & & \\
4 & $\mathrm{CC}$ & & 2.2 & & 3.3 & & & & \\
& $\mathrm{CS}$ & & & & & 4.0 & & & \\
\hline
\end{tabular}

Significance of treatment factors in an unbalanced ANOVA: GEN (genotype), $P<0.05$; CUL (type of culture), CC (callus culture), CS (cell suspension culture), differences not significant; $\mathrm{W}$ (weeks in culture), $P<0.001$.

majority of $L$. multiflorum $\times F$. arundinacea pentaploid hybrids permanently failed to flower following cell suspension culture (even after gibberellin treatment). Flowering was earlier in 1993 than in 1992 and occurred over a more restricted period $(12 / 5$ to $24 / 5$ / 93 ). Normal heads were produced and seed production was sufficient to sow field plots of half-sib families (Table 1). These will be used to provide further information on the value of somaclonal variation in tall fescue breeding.

\section{Cytogenetics and male fertility}

All the plants had the same chromosome number $(2 n=42)$ except plant 11 (genotype 1) which was a mixaploid $(2 n=42 / 44)$. Ahloowalia (1983) found that the Lolium triploid hybrids initially derived from callus culture were $2 n=21$, whereas aneuploidy appeared with longer periods of culture. Reed \& Conger (1985), Eizenga (1989) and Dahleen \& Eizenga (1990) commonly found aneuploidy after callus culture of $F$. arundinacea.

Among the plants used for meiotic analysis in 1993 (Table 3), only plants 12 (genotype 3 ) and 20 (genotype 2) showed no abnormalities, although there was low pollen stainability in the former. Plants 14, 15, 16, 18 and 19 , which did not flower in the first year, contained aberrations. The existence of reciprocal translocations and the possibility of inversions in some plants was revealed by the occurrence of quadrivalents in euploid cells and by chromatin bridges (Fig. 2a,b). The low frequency of cells with quadrivalents or fragments indicated that the lengths of the translocated fragments and/ or inversions must be small. Three out of 18 plants (16.7 per cent) presented multivalents, but one of them 
Table 3 Meiotic analysis of somaclones from Festuca arundinacea

\begin{tabular}{|c|c|c|c|c|c|c|c|c|}
\hline \multirow[b]{2}{*}{ Genotype } & \multirow{2}{*}{$\begin{array}{l}\text { Plant } \\
\text { no. }\end{array}$} & \multirow[b]{2}{*}{ Culture } & \multirow[b]{2}{*}{$\mathrm{M} / \mathrm{T}$} & \multirow[b]{2}{*}{ AIb } & \multicolumn{4}{|c|}{ Mean MI associations } \\
\hline & & & & & I & II & III & IV \\
\hline 1 & 11 & $1 \mathrm{mCC}+2 \mathrm{wCS}$ & 0.55 & 0.30 & 0.83 & 19.61 & 0.72 & 0.00 \\
\hline 2 & 2 & $1 \mathrm{mCC}+8 \mathrm{wCS}$ & 0.15 & 0.20 & 0.20 & 20.90 & 0.00 & 0.00 \\
\hline 2 & 5 & $1 \mathrm{mCC}+2 \mathrm{wCS}$ & 0.30 & 0.15 & 0.00 & 21.00 & 0.00 & 0.00 \\
\hline 2 & 19 & $1 \mathrm{mCC}+5 \mathrm{wCS}$ & 0.20 & 0.00 & 0.20 & 20.90 & 0.00 & 0.00 \\
\hline 2 & 20 & $2 \mathrm{mCC}$ & 0.00 & 0.00 & 0.20 & 20.90 & 0.00 & 0.00 \\
\hline 2 & 26 & $2 \mathrm{mCC}$ & 0.15 & 0.00 & 0.40 & 20.80 & 0.00 & 0.00 \\
\hline 2 & 28 & $2 \mathrm{mCC}$ & 0.15 & 0.15 & 0.80 & 20.60 & 0.00 & 0.00 \\
\hline 2 & 29 & $2 \mathrm{mCC}$ & 0.25 & 0.20 & 0.20 & 20.90 & 0.00 & 0.00 \\
\hline 2 & 32 & $2 \mathrm{mCC}$ & 0.25 & 0.15 & 1.80 & 20.10 & 0.00 & 0.00 \\
\hline 2 & 73 & $18 \mathrm{wCC}$ & 0.00 & 0.30 & 0.20 & 20.90 & 0.00 & 0.00 \\
\hline 3 & 10 & $1 \mathrm{mCC}$ & 0.85 & - & - & - & - & - \\
\hline 3 & 12 & $1 \mathrm{mCC}$ & 0.00 & 0.00 & 0.40 & 20.80 & 0.00 & 0.00 \\
\hline 3 & 13 & $1 \mathrm{mCC}$ & 0.49 & 0.30 & 0.60 & 20.70 & 0.00 & 0.00 \\
\hline 3 & 14 & $1 \mathrm{mCC}$ & 0.15 & 0.15 & 23.60 & 9.20 & 0.00 & 0.00 \\
\hline 3 & 15 & $1 \mathrm{mCC}+2 \mathrm{wCS}$ & 0.15 & 0.00 & 1.10 & 20.40 & 0.00 & 0.00 \\
\hline 3 & 41 & $2 \mathrm{mCC}$ & 0.50 & 0.20 & 0.60 & 20.70 & 0.00 & 0.00 \\
\hline 4 & 6 & $1 \mathrm{mCC}$ & 0.10 & 0.15 & - & - & - & - \\
\hline 4 & 16 & $1 \mathrm{mCC}+10 \mathrm{wCS}$ & 0.35 & - & - & - & - & \\
\hline 4 & 18 & $1 \mathrm{mCC}$ & 0.15 & 0.15 & 0.10 & 20.90 & 0.00 & 0.00 \\
\hline 4 & 36 & $2 \mathrm{mCC}$ & 0.00 & 0.15 & 0.10 & 20.60 & 0.00 & 0.20 \\
\hline 4 & 37 & $2 \mathrm{mCC}$ & 0.00 & 0.30 & 0.15 & 20.20 & 0.05 & 0.35 \\
\hline
\end{tabular}

$\mathrm{M} / \mathrm{T}$, micronuclei per tetrad (per dyad in plant 29); AIb, anaphase I bridges per pollen mother cell (PMC); mean MI associations, mean metaphase I associations per PMC (estimates based on 20 observations, 18 in plant 11 and seven in plant 13); $\mathrm{CC}$, callus culture; $\mathrm{CS}$, cell suspension; w, weeks; $\mathrm{m}$, months.

(plant 11, genotype 1) only displayed them in tetrasomic cells; the other two ( 11.1 per cent) belonged to genotype 4 (plants 36 and 37, after 2 months in callus culture). Evidence of reciprocal translocations was found by Eizenga (1989) but not by Reed \& Conger (1985). Plant 26 (genotype 2, 2 months, callus culture) contained a deletion, as indicated by a heteromorphic bivalent in metaphase I.

Sticky chromosomes were common, and could be the cause of chromatin bridges without fragments which last until telophase I, as proposed by Reed \& Conger (1985). Figure 2(c) illustrates the occurrence of chromatin fibres linking bivalents in a small proportion of the pollen mother cells (PMCs) of plant 36. This could be the result of squashing sticky chromosomes or chromatin extrusion. A similar observation was also found in the mitosis of another plant. In plant 2 (genotype 2, 1 month of callus culture followed by 8 weeks' cell suspension), one circular chromosome was spotted in metaphase II, which may be an isochromosome since a heteromorphic bivalent was seen in metaphase I. Micronuclei at the dyad and tetrad stage were observed in cells of plants with anaphase I fragments which did not migrate and also in plants which presented 'laggards' and no anaphase I fragments. Asynchrony was common, with cells ranging from metaphase I to metaphase II in the same anther. These phenomena have also been reported by Ahloowalia (1983). Plant 14 (genotype 3, 1 month's callus culture), showed strong asynapsis (or desynapsis), but other plants also contained univalents and $\mathrm{H}$-shaped bivalents in metaphase I and lagging univalents in anaphase I.

Asynapsis was also reported in euploid plants by Eizenga (1989), although male fertility was not as reduced as in this study. In the case of the majority of the plants derived from genotype 3 and genotype 4 (Table 1), pollen stainability (PS) was below 20 per cent. Pollen grains looked round and full at an early stage, but mature grains in older spikelets of the same head had shrunk and were empty or their content was restricted to one side (Fig. 2d). In plant 2 (genotype 2), the anthers released normal pollen grains only after thorough tapping and squashing, and the pollen remained in clusters. The tapetum seemed to degener- 

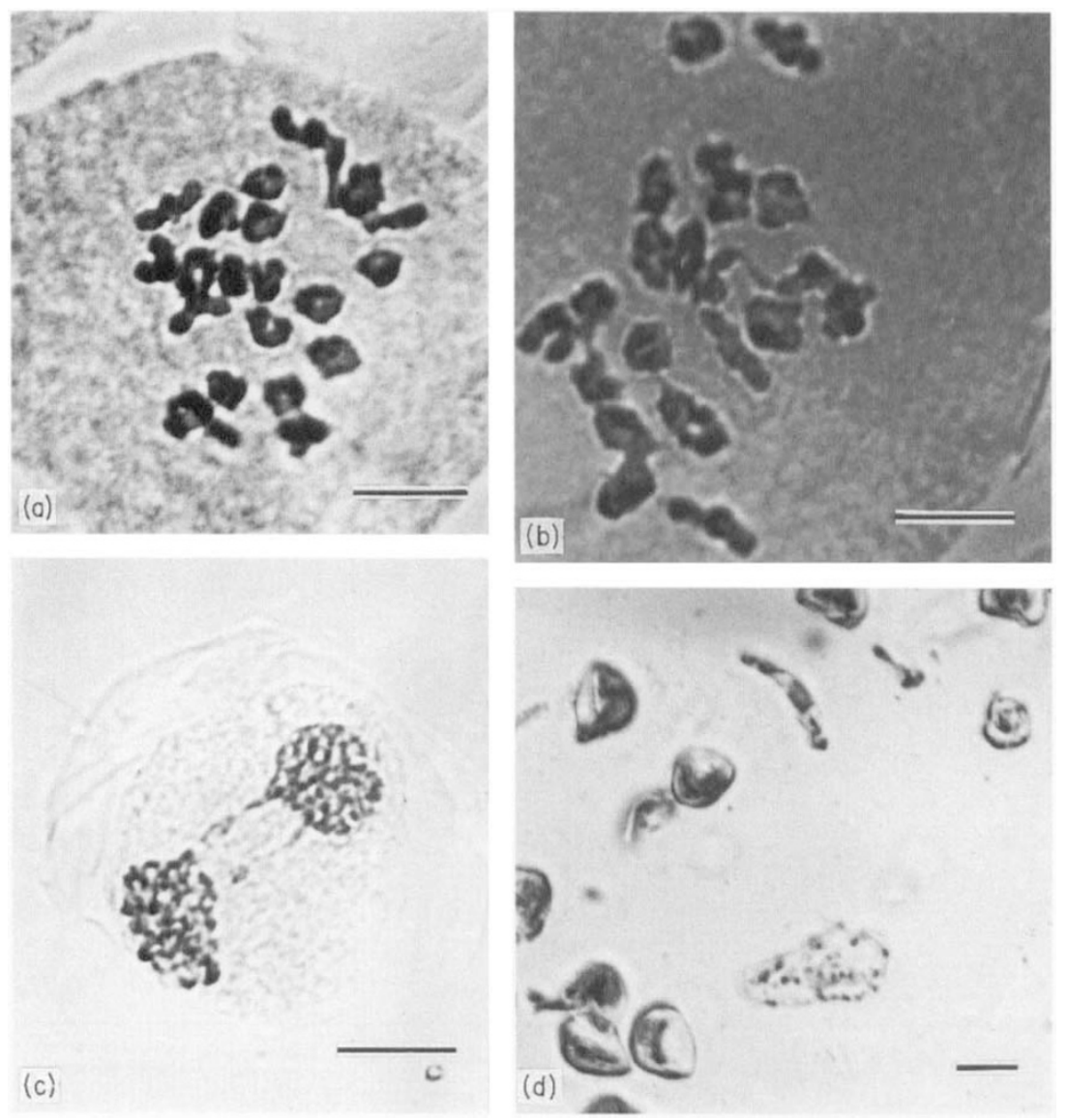

Fig. 2 (a) Two quadrivalents in metaphase I (plant 37). (b) Chromatin bridges in late metaphase I (plant 37). (c) Chromosomes linked by chromatin fibres (plant 36). (d) Mature pollen grains (plant 36). Scale bar: a, b, c, $10 \mu \mathrm{m} ; \mathrm{d}, 20 \mu \mathrm{m}$.

Table 4 PGI-2 banding patterns of $F$. arundinacea somaclones regenerated after in vitro culture

\begin{tabular}{|c|c|c|c|c|c|c|c|}
\hline \multirow[b]{3}{*}{$P G I-2$ alleles } & \multicolumn{7}{|c|}{ Genotypes } \\
\hline & \multirow{2}{*}{$\begin{array}{c}1 \\
a^{+} a c d \\
\text { or } a^{+} a b c d\end{array}$} & \multicolumn{3}{|c|}{2} & \multirow{2}{*}{$\begin{array}{c}3 \\
a^{+} a d\end{array}$} & \multicolumn{2}{|c|}{4} \\
\hline & & $a^{++} a^{+}$acde & $a^{++} a^{+}$ade & $a^{+}$ade & & $a^{+} a d e$ & $a^{+} a d$ \\
\hline$(-) e$ & & - & - & - & & - & \\
\hline (de) & & - & - & - & & - & \\
\hline$d$ & - & - & - & - & - & - & - \\
\hline$(c d)$ & - & - & & & & & \\
\hline$c$ & - & - & - & - & & - & \\
\hline$\left(b c, a d, a^{+} e\right)$ & - & - & - & - & - & - & - \\
\hline$b$ & - & - & - & - & - & - & - \\
\hline$\left(a b, a^{+} c, a^{++} d\right)$ & - & - & - & - & & - & \\
\hline$a$ & - & - & - & - & - & - & - \\
\hline$\left(a^{+} a\right)$ & - & - & - & - & - & - & - \\
\hline$a^{+}$ & - & - & - & - & - & - & - \\
\hline$\left(a^{++} a^{+}\right)$ & & - & - & & & & \\
\hline$(+) a$ & & - & - & & & & \\
\hline
\end{tabular}

In genotypes 2 and 4 , the first zymogram belongs to the control plant, and the others to the abnormal plants.

ate in all cases, so that the main cause of pollen sterility was apparently abnormal microsporogenesis caused by a malfunctioning of the tapetum (Ahokas, 1978). All plants which had a higher mature PS (including geno- type 1 and half of the plants from genotype 2) also possessed more viable pollen grains in younger spikelets. The relatively high seed-set obtained in plants with partial male sterility indicates that oogenesis was more 
tolerant to chromosome disturbances, which is a wellknown phenomenon (Jenkin, 1933).

In a hierarchical analysis of variance of plants scored quantitatively, significant differences at the 5 per cent probability level were obtained for pollen stainability among somaclones derived from different genotypes (genotype $2>$ genotype $4>$ genotype 3 ). Other plants were only scored qualitatively for this trait, but they confirmed that frequent male sterility occurred (Table $1)$, which was not related to time of heading. There were no significant linear correlations between meiotic measurements and plant traits (data not shown).

There were no significant differences between callus and cell suspension cultures, or among periods in culture, for any cytological measurement. The greatest pollen sterility ( 5 per cent PS) was shown by plant 15 from genotype 3 , obtained after 2 weeks' cell suspension culture. In genotype 2 , the highest percentage of pollen stainability was found in plant 73 from 18 weeks of callus culture, whereas a low percentage was sometimes achieved in plants from 8 weeks of callus culture (Table 1). The only plant (11) analysed from genotype 1 was a mixaploid with euploid and tetrasomic cells and was obtained after 1 month in callus culture and 2 weeks' cell suspension. The isochromosome appeared in a plant obtained after 1 month's callus culture plus 8 weeks' cell suspension. However, the only plant which did not flower (number 30 from genotype 2) was obtained after 2 months of callus culture, and reciprocal translocations were only found in plants 36 and 37 (genotype 4), which were regenerated after 2 months of callus culture.

In conclusion, somaclonal variation was common in regenerants of all four genotypes, but there was little effect of either type or duration of culture, possibly because of the relatively short culture periods involved.

\section{PGI-2 zymograms}

Although the original genotype 1 was no longer available, zymograms of the three derived plants $(1,9$ and 11) were recorded once in 1992 and again in 1993. In both cases, the three plants had the same zymogram ( $a^{+}$acd or $a^{+} a b c d$ fit the bands observed) (Table 4). Assuming that the original plant had the same zymogram, it appears that the isozymes were unchanged by culture conditions ( 1 month's callus culture followed by 2 weeks of cell suspension for all three plants), and remained stable from year to year.

The 14 plants from genotype 3 all gave the same zymogram $\left(a^{+} a d\right)$ which was also the zymogram found for the control plant (cultured without hormones). Some plants from this genotype were derived from 1 month's callus culture, others were obtained after an additional 2 weeks of cell suspension culture and others were from 2 months' callus culture. Thus plants derived from both genotypes 1 and 3 remained unchanged in $P G I-2$ expression following various culture treatments.

The control plant of genotype 4 gave the zymogram $a^{+}$ade. The eight plants derived from this genotype produced the same zymogram except for plant 38, which was $a^{+} a d$, having lost the $e$ allele. This gives a frequency of 12.5 per cent abnormal plants, but the sampling error is too high to rely on this estimate.

The control plant of genotype 2 gave a zymogram of $a^{++} a^{+} a c d e$. Out of 48 plants derived from this genotype, three showed abnormalities $(6.2$ per cent). Plant 52 had lost the $c$ allele $\left(a^{++} a^{+}\right.$ade $)$and plants 38 and 44 had lost both the $c$ and $a^{++}$alleles.

Deletions of $P G I-2$ alleles, particularly $c$, has already been reported in $F$. arundinacea after cell suspension culture (Humphreys \& Dalton, 1991). However, they obtained PGI-2 aberrations after 26 weeks which was a far longer culture period than that used in the present work. Therefore, callus culture also seems to produce a high PGI-2 instability, although all the plants which showed differences had been in culture for at least 2 months. Dahleen \& Eizenga (1990) also found allele inactivity at the PGI-2 locus after 12 weeks' callus culture. Nevertheless, plant 86 (genotype 2), which had been under such conditions for 23 weeks, did not show instability. Humphreys \& Dalton (1991) demonstrated that PGI-2 instability was related to reduced chromosome numbers, but in the case of pentaploid hybrids Lolium multiflorum $\times$ Festuca arundinacea isozyme deletions were not always related to chromosome loss (Humphreys \& Dalton, 1992), as was also found here.

We can conclude that in vitro culture may produce severe pollen sterility, as well as chromosome mutations and PGI-2 instability within a short period of time. The extent of the abnormalities is influenced by plant genotype, but there is no clear effect of the type of culture used. During longer periods of culture, cell suspensions would be expected to have a more mutagenic effect than callus because the small, fast-growing cell colonies are in direct contact with mutagenic medium, without intercell competition.

The low frequency and short life of both embryogenic and regenerative responses, combined with the rapid buildup of genetic instability in these genotypes, indicates that unselected material may not be directly suitable for genetic manipulation using cell cultures. Prior introduction of traits which enhance performance in tissue culture may be necessary or it may be feasible to use alternative techniques which avoid the use of cell cultures. 


\section{Acknowledgements}

A.G. would like to thank the whole Cytogenetics group of IGER for kindly allowing the use of the laboratory equipment and for help and advice at every stage, Professor M.D. Hayward for allowing the use of the isozyme laboratory, and F. Potter for the statistical analyses. This work was carried out during the tenure of a postdoctoral grant from the Spanish CICYT.

\section{References}

AHLOOWALIA, B. S. 1983. Spectrum of variation in somaclones of triploid ryegrass. Crop Sci., 23, 1141-1147.

AHOKAS, H. 1978. Cytoplasmic male sterility in barley. 1. Anther and pollen characteristics of $\mathrm{msml}$, restored and partially restored $m s m l$ genotypes. Z. Pflzücht., 81, 327-332.

BAYLISS, M. w. 1980. Chromosomal variation in plant tissue cultures. In: Vassil, I. K. (ed.) International Review of Cytology, Supplement IIA: Perspectives in Plant Cell and Tissue Culture, pp. 113-144. Academic Press, New York.

BENSON, E. 1990. Free Radical Damage in Stored Plant Germplasm. IBPGR, Rome.

DAHLEEN, L. S. AND EIZENGA, G. C. 1990. Meiotic and isozymic characterization of plants regenerated from euploid and selfed monosomic tall fescue embryos. Theor. Appl. Genet., 79, 39-44.

DALTON, S. J. 1988. Plant regeneration from cell suspension protoplasts of Festuca arundinacea Schreb. (tall fescue) and Lolium perenne L. (perennial ryegrass). J. Plant Physiol., 132, 170-175.
EIZENGA, G. C. 1989. Meiotic analyses of tall fescue somaclones. Genome, 32, 373-379.

GOULD, A. R. 1984. Control of the cell cycle in cultured plant cells. CRC Critical Rev. Plant Sci., 1, 315-344.

HAYWARD, M. D. AND McADAM, N. J. 1977. Isozyme polymorphism as a measure of distinctiveness and stability in cultivars of Lolium perenne. Z. Pflzücht., 79, 59-68.

HUMPHREYS, M. W. AND DALTON, S. J. 1991. Stability at the phosphoglucoisomerase $(P G I / 2)$ locus in Festuca arundinacea plants regenerated from cell suspension and protoplast culture. Genome, 34, 59-65.

HUMPHREYS, M. W. AND DALTON, S. J. 1992. Stability at the phosphoglucoisomerase $(P G I / 2)$ locus in Lolium multiflorum $(2 n=4 x=28) \times$ Festuca arundinacea $(2 n=6 x=42)$ plants regenerated from cell suspension. Genome, 35, 461-467.

JENKIN, T. J. 1933. Interspecific and intergeneric hybrids in herbage grasses. Initial crosses. J. Genet., 28, 205-264.

KARP, A. 1991. On the current understanding of somaclonal variation. Oxford Surv, Plant Mol. Cell Biol., 7, 1-58.

LEE, M. AND PHILLIPS, R.C. 1988. The chromosomal basis of somaclonal variation. Ann. Rev. Plant Physiol. Plant Mol. Biol., 39, 413-438.

LEWIS, E. J., HUMPHREYS, M. W. AND CATON, M. P. 1980. Disomic inheritance in Festuca arundinacea Schreb. Z. Pflzücht., 84, 335-341.

MURASHIGE, T. AND SKOOG, F. 1962. A revised medium for rapid growth and bioassay with tobacco tissue cultures. Physiol. Plant, 15, 473-497.

REED, J. N. AND CONGER, B. v. 1985. Meiotic analyses of tall fescue plants regenerated from callus cultures. Env. Exp. Bot., 25, 277-284.

SNow, R. 1963. Alcoholic hydrochloric acid-carmine as a stain for chromosome squash preparations. Stain Technol., 38, 9-13. 